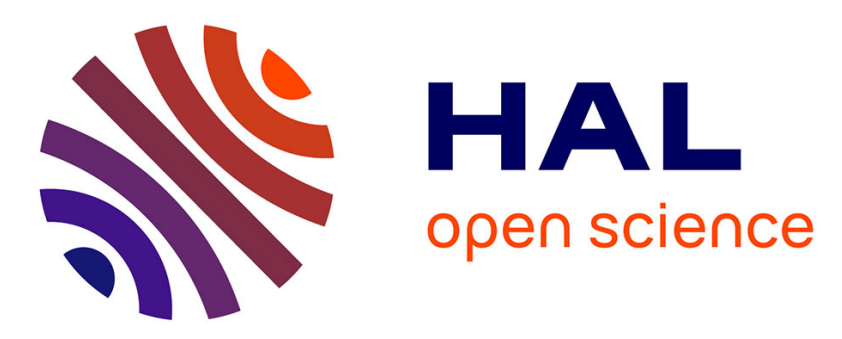

\title{
JAK Inhibition in the Aicardi-Goutières Syndrome
}

Bénédicte Neven, Buthaina Al Adba, Marie Hully, Isabelle Desguerre, Claire

Pressiat, Natalie Boddaert, Darragh Duffy, Gillian I. Rice, Luis Seabra, Marie-Louise Frémond, et al.

\section{- To cite this version:}

Bénédicte Neven, Buthaina Al Adba, Marie Hully, Isabelle Desguerre, Claire Pressiat, et al.. JAK Inhibition in the Aicardi-Goutières Syndrome. New England Journal of Medicine, 2020, 383 (22), pp.2190-2193. 10.1056/NEJMc2031081 . pasteur-03155975

\section{HAL Id: pasteur-03155975}

https://hal-pasteur.archives-ouvertes.fr/pasteur-03155975

Submitted on 2 Mar 2021

HAL is a multi-disciplinary open access archive for the deposit and dissemination of scientific research documents, whether they are published or not. The documents may come from teaching and research institutions in France or abroad, or from public or private research centers.
L'archive ouverte pluridisciplinaire HAL, est destinée au dépôt et à la diffusion de documents scientifiques de niveau recherche, publiés ou non, émanant des établissements d'enseignement et de recherche français ou étrangers, des laboratoires publics ou privés.

$$
\text { Copyright }
$$


First, we found that the incidence of atypical femur fracture was unrelated to BMD and only weakly related to age. Second, when we performed a subgroup analysis in the Kaiser Permanente cohort that was limited to women who were older than 65 years of age and who had a BMD T-score of less than -2.5 , we found an incidence of atypical femur fracture similar to the incidence in the overall cohort (unpublished data). The correspondents question whether we overestimated the fracture benefit of 5 to 10 years of alendronate, since the FLEX trial ${ }^{1}$ and observational data ${ }^{2}$ showed no increase in the risk of clinical fracture after alendronate was discontinued after 5 years. However, studies involving patients with 5 years of previous treatment are not relevant, since our estimate of the fractures that were prevented with alendronate was based on a comparison of women who were never treated with those who were continuously treated. We agree that our findings that show large decreases in the risk of atypical femur fracture after the discontinuation of alendronate provide support for a drug holiday after 5 years, particularly for women at lower risk.

Garton questions whether an underestimation of the incidence of atypical femur fracture biases the ratio of such fractures to fragility fractures. However, we think that our adjudication, starting with all femoral-shaft or subtrochanteric fractures, identified virtually all complete unilateral and bilateral atypical femur fractures. However, incomplete fractures would not have been included unless they had been prophylactically repaired. We agree that accumu- lating microdamage is part of the pathophysiology of atypical femur fracture, but its effect on only a small minority of patients remains unexplained. ${ }^{3}$ Regarding the consequences of atypical femur fracture as compared with hip fracture, several studies have suggested similar mortality ${ }^{4}$ after either type of fracture, although surgical repair of atypical femur fractures can be more challenging. ${ }^{3}$

Dennis M. Black, Ph.D.

University of California, San Francisco

San Francisco, CA

dennis.black@ucsf.edu

Richard Eastell, M.D.

University of Sheffield

Sheffield, United Kingdom

Annette L. Adams, Ph.D.

Kaiser Permanente Southern California

Pasadena, CA

Since publication of their article, the authors report no further potential conflict of interest.

1. Black DM, Schwartz AV, Ensrud KE, et al. Effects of continuing or stopping alendronate after 5 years of treatment: the Fracture Intervention Trial Long-term Extension (FLEX): a randomized trial. JAMA 2006;296:2927-38.

2. Adams AL, Adams JL, Raebel MA, et al. Bisphosphonate drug holiday and fracture risk: a population-based cohort study. J Bone Miner Res 2018;33:1252-9.

3. Black DM, Abrahamsen B, Bouxsein ML, Einhorn T, Napoli N. Atypical femur fractures: review of epidemiology, relationship to bisphosphonates, prevention, and clinical management. Endocr Rev 2019;40:333-68.

4. Kharazmi M, Hallberg P, Schilcher J, Aspenberg P, Michaëlsson K. Mortality after atypical femoral fractures: a cohort study. J Bone Miner Res 2016;31:491-7.

DOI: 10.1056/NEJMc2029828

\section{JAK Inhibition in the Aicardi-Goutières Syndrome}

TO THE EDITOR: Some reports, ${ }^{1-3}$ including that of Vanderver et al. (Sept. 3 issue), ${ }^{4}$ have indicated the potential of Janus kinase 1 (JAK1) blockade in the treatment of type I interferonopathies. We describe here the onset of the Aicardi-Goutières syndrome, despite the use of ruxolitinib for 10 months, in a patient who had been presymptomatic.

A 4-month-old male infant with biallelic
RNASEH2B mutations was identified after an older sibling received a diagnosis of the AicardiGoutières syndrome. The infant's development had been normal until that time, but he had markers that were suggestive of interferon-signaling activation (Fig. S1 in the Supplementary Appendix, available with the full text of this letter at NEJM.org). Therefore, when he was 5 months of age, we initiated therapy with ruxolitinib at a 
dose of $5 \mathrm{mg}$ twice daily. When he was 11 months of age, the dose was increased to $7.5 \mathrm{mg}$ twice daily (1 mg per kilogram of body weight per day).

At 12 months of age, the patient's neurologic status remained normal. At 13 months of age, he had weekly fevers. Ruxolitinib was discontinued twice, for 3 days on each occasion, in the 14th month of life. His immunization history included the administration of hepatitis A vaccine at 13 months of age (see the Supplementary Appendix). At 15 months of age, up to which time his neurologic status was normal, he had an abrupt onset of irritability and neurologic deterioration. At 17 months of age, he had spastic-dystonic tetraparesis and was no longer able to speak.

We observed that the concentration of ruxolitinib in the patient's cerebrospinal fluid (CSF) was approximately $10 \%$ of that in the plasma; a similar finding was observed in three other patients with the Aicardi-Goutières syndrome (Table S1). Better penetration into the central nervous system or combination therapy ${ }^{5}$ might have prevented disease manifestation.

Bénédicte Neven, M.D., Ph.D.

Hôpital Necker-Enfants Malades

Paris, France

benedicte.neven@aphp.fr

\author{
Buthaina Al Adba, M.D. \\ Sidra Medicine \\ Doha, Qatar \\ Marie Hully, M.D. \\ Isabelle Desguerre, M.D. \\ Hôpital Necker-Enfants Malades \\ Paris, France
}

Claire Pressiat, Ph.D.

Hôpitaux Universitaires Henri Mondor

Creteil, France

Natalie Boddaert, M.D., Ph.D.

Hôpital Necker-Enfants Malades

Paris, France

Darragh Duffy, Ph.D.

Institut Pasteur

Paris, France

Gillian I. Rice, Ph.D.

University of Manchester

Manchester, United Kingdom

Luis Seabra, M.Sc.

Marie-Louise Frémond, M.D., Ph.D.

Institut Imagine

Paris, France

Stéphane Blanche, M.D.

Hôpital Necker-Enfants Malades

Paris, France

YanickJ. Crow, M.D., Ph.D.

University of Edinburgh

Edinburgh, United Kingdom

Figure 1 (next page). Interferon-Signaling Gene (ISG) Expression Scores in the Context of Infection and Vaccination and Aicardi-Goutières Syndrome Scores in Patients Treated with Baricitinib.

In our study, one patient with homozygous RNASEH2B mutations had elevated ISG scores after influenza vaccination, which had been administered hours before the sample was obtained, and during a viral illness with fever (Panel A, left graph). Control values (from patients without interferonopathy) are shown in the right graph. In a different cohort, ${ }^{1}$ a patient who had the Aicardi-Goutières syndrome with homozygous SAMHD1 deletions had a decrease in ISG scores and improved clinical findings during baricitinib therapy (Panel B, left graph). During the study, the patient had three infections (a proteus urinary tract infection [UTI], sinusitis, and strep throat), which were treated with antibiotic agents and were associated with elevated ISG scores. Control values (from patients without interferonopathy or with CANDLE [chronic atypical neutrophilic dermatosis with lipodystrophy and elevated temperatures] or SAVI [stimulator of interferon genes-associated vasculopathy with onset in infancy]) are shown in the right graph. The specific methods for assessing the ISG scores shown in Panels A and B varied between the two study cohorts ${ }^{1,2}$; in both cases, higher scores indicate greater interferon signaling. In an additional patient, baricitinib therapy was interrupted owing to concerns with infection (Panel C). Subsequently, neurologic skills, as measured by the AicardiGoutières syndrome scale (on which scores range from 0 to 11 , with increased scores indicating discrete milestones gained), ${ }^{3}$ were lost. Evaluation of developmental milestones, assessed according to the Aicardi-Goutières syndrome scale, is shown for two sibling pairs in our study (Panel D); shown are scores from before treatment, the baseline visit at the initiation of baricitinib treatment, and the last available scores. The older siblings (red) met developmental milestones while they were receiving baricitinib, and the younger siblings (blue) met age-appropriate development milestones as of the last evaluation. Asterisks indicate the initiation of baricitinib therapy. 


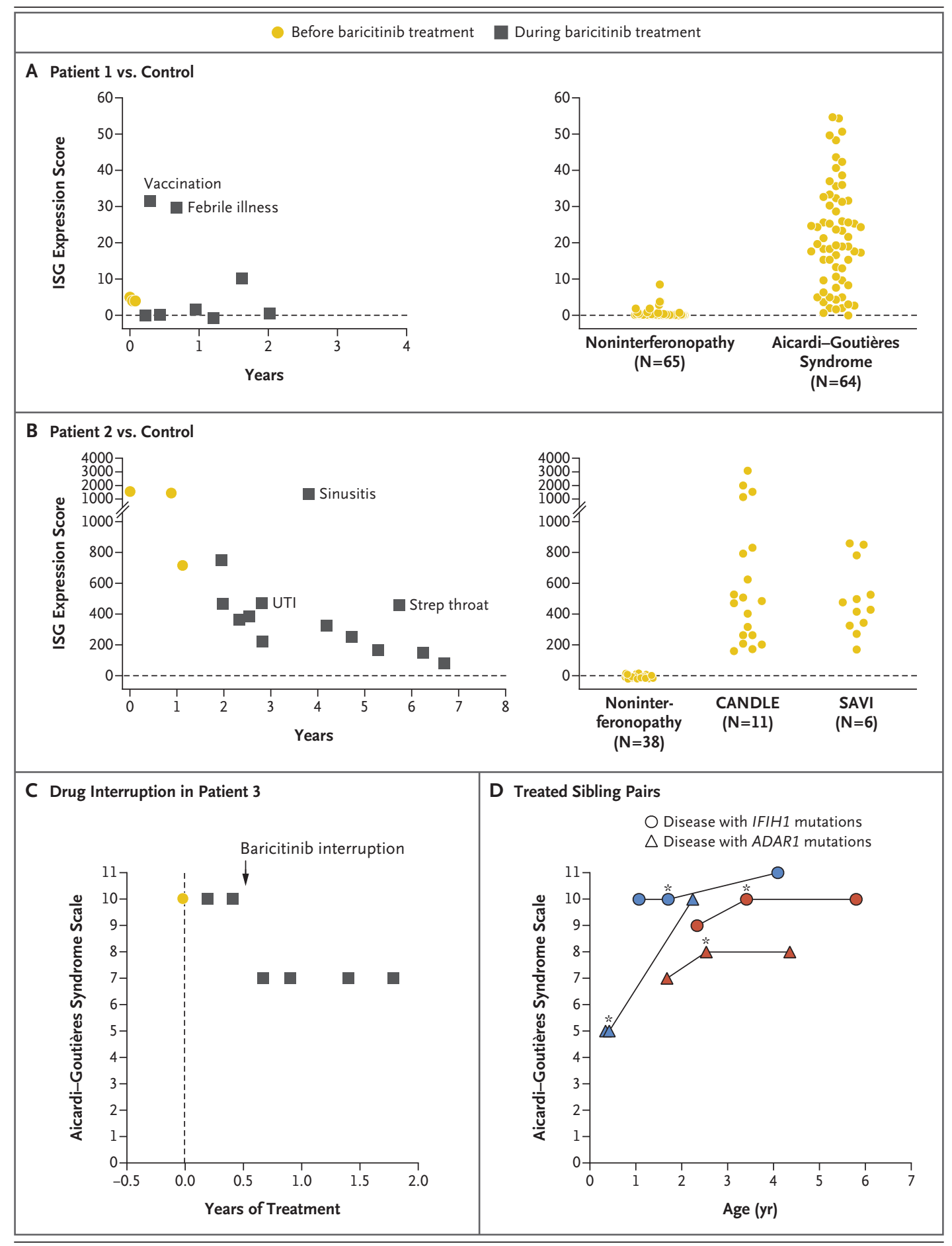

N ENGLJ MED 383;22 NEJM.ORG NOVEMBER 26, 2020

The New England Journal of Medicine

Downloaded from nejm.org at Institut Pasteur - CeRIS on March 16, 2021. For personal use only. No other uses without permission. Copyright (c) 2020 Massachusetts Medical Society. All rights reserved. 
Dr. Crow reports receiving consulting fees, paid to his institution, from Biogen. No other potential conflict of interest relevant to this letter was reported.

1. Frémond M-L, Rodero MP, Jeremiah N, et al. Efficacy of the Janus kinase $1 / 2$ inhibitor ruxolitinib in the treatment of vasculopathy associated with TMEM173-activating mutations in 3 children. J Allergy Clin Immunol 2016;138:1752-5.

2. Kothur K, Bandodkar S, Chu S, et al. An open-label trial of JAK 1/2 blockade in progressive IFIH1-associated neuroinflammation. Neurology 2018;90:289-91.

3. Briand C, Frémond M-L, Bessis D, et al. Efficacy of JAK1/2 inhibition in the treatment of chilblain lupus due to TREX1 deficiency. Ann Rheum Dis 2019;78:431-3.

4. Vanderver A, Adang L, Gavazzi F, et al. Janus kinase inhibition in the Aicardi-Goutières syndrome. N Engl J Med 2020;383: 986-9.

5. Rice GI, Meyzer C, Bouazza N, et al. Reverse-transcriptase inhibitors in the Aicardi-Goutières syndrome. N Engl J Med 2018;379:2275-7.

DOI: 10.1056/NEJMc2031081

THE AUTHORS AND A COlleague Reply: The Aicardi-Goutières syndrome is a disease of persistent interferon dysregulation. Neven et al. point to the importance of identifying potential disease triggers. Across two separate cohorts of patients who had interferonopathies treated with baricitinib (from our study and from a study by Montealegre Sanchez et al. ${ }^{1}$ ), there are examples of patients with the Aicardi-Goutières syndrome who had scores indicating elevated interferonsignaling gene (ISG) expression related to environmental factors, such as infection and vaccination (Fig. 1A and 1B).

In addition, early and uninterrupted treatment with JAK inhibitors may be important. In one patient in our study, baricitinib therapy was interrupted for 2 days because of infection concerns, and the dose was subsequently reduced. While baricitinib was not being administered, this patient lost neurologic skills, which have not been regained despite resumption of the dose (Fig. 1C). Two patients in our study had younger siblings who had early symptoms one with toe walking, and the other with torticollis - and who were treated with baricitinib (Fig. 1D). To date, with baricitinib therapy, the younger siblings have met age-appropriate mile- stones without regression. We did not assess CSF pharmacokinetics in our study.

The Aicardi-Goutières syndrome is a disease of fluctuating interferon dysregulation, which can be exacerbated by environmental factors. Although there are gaps in knowledge regarding dose levels, target engagement, CSF penetration, environmental risk factors, and the comparison of different JAK inhibitors, our work suggests that early identification and consistent treatment with JAK inhibitors may positively affect neurologic outcomes in patients with the AicardiGoutières syndrome.

Laura Adang, M.D., Ph.D.

Children's Hospital of Philadelphia

Philadelphia, PA

Raphaela Goldbach-Mansky, M.D., M.H.S.

National Institute of Allergy and Infectious Diseases

Bethesda, MD

Adeline Vanderver, M.D.

Children's Hospital of Philadelphia

Philadelphia, PA

vandervera@email.chop.edu

Dr. Goldbach-Mansky reports receiving grant support for translational studies under a government Cooperative Research and Development Agreement from Eli Lilly, Sobi, Novartis, and Regeneron Pharmaceuticals. Since publication of their letter, Drs. Adang and Vanderver report no further potential conflict of interest.

1. Montealegre Sanchez GA, Reinhardt A, Ramsey S, et al. JAK1/2 inhibition with baricitinib in the treatment of autoinflammatory interferonopathies. J Clin Invest 2018;128:304152.

2. Armangue T, Orsini JJ, Takanohashi A, et al. Neonatal detection of Aicardi Goutières syndrome by increased C26:0 lysophosphatidylcholine and interferon signature on newborn screening blood spots. Mol Genet Metab 2017;122:1349.

3. Adang LA, Gavazzi F, Jawad AF, et al. Development of a neurologic severity scale for Aicardi Goutières Syndrome. Mol Genet Metab 2020;130:153-60.

DOI: 10.1056/NEJMc2031081

Correspondence Copyright (c) 2020 Massachusetts Medical Society.

\section{INSTRUCTIONS FOR LETTERS TO THE EDITOR}

Letters to the Editor are considered for publication, subject to editing and abridgment, provided they do not contain material that has been submitted or published elsewhere. 